\title{
Sediments and Stratigraphy in Rockshelters and Caves: A Personal Perspective on Principles and Pragmatics
}

\author{
William R. Farrand \\ Museum of Anthropology, The University of Michigan, Ann Arbor, Michigan \\ 48109-1079
}

\begin{abstract}
Over the last half century the study of rockshelter and cave sediments has evolved from straightforward descriptive analysis to sophisticated examination on several scales-from field observations to bulk laboratory analyses to microscopic examination. Still an integrated theory to guide the interpretation of these analyses does not exist, in part because of the idiosyncratic nature of individual caves and rockshelters. This paper reviews studies that couple field observations with laboratory analyses including particle size, pebble morphology, chemical, and mineralogical studies to provide, first, the necessary basic description of the sediments and, second, an interpretation of the environment of sedimentation. These studies can lead to an understanding of site-formation processes during human occupation, and eventually to a reconstruction of local and, in some cases, regional paleoclimates. Furthermore, sediment study is essential for intrasite correlation, independent of artifact, faunal, floral, and radiometric techniques. Finally, it is emphasized that close cooperation among sedimentologists, archaeologists, and biological specialists during planning, excavation, and interpretative stages is crucial to a successfully integrated study. (C) 2001 John Wiley \& Sons, Inc.
\end{abstract}

\section{INTRODUCTION}

Sedimentology can provide a number of details on human activities in a cave or rockshelter, on the character of the natural environment inside the cave, and information on the changing nature or configuration of the cave or rockshelter itself. In some cases, the geological features inside the cave or rockshelter can shed light on the external environment as well, as we shall see below. Of course, the study of plant and animal remains (paleoethnobotany and zooarchaeology, respectively) go hand-in-hand with geoarchaeology to elucidate the paleoenvironment.

The medium in which this information is embedded is sediment that accumulated in the cave or rockshelter before, during, and after any episode of human activity. It is important to recognize that the sediment constitutes the site! All the artifacts, structural features, and biological remains embedded in the sediments may be entirely of natural origin (archaeologically barren) or may be largely introduced by humans, but most commonly there is some mixing of natural and anthropogenic deposits. It is an important challenge for the archaeological sedimentologist to sort out the different components.

The following presentation is based largely on my own experiences in the Med- 
iterranean region and in western Europe over nearly 40 years. However, the discussion takes into account the works of many other colleagues (e.g., Bonifay, 1962; Goldberg, 1973; Collcutt, 1979; Laville et al., 1980; Butzer, 1981; Campy and Chaline, 1993; Bailey and Woodward, 1997; among many others). The methodology and parameters discussed below are generally used by most of these workers, although the applications, emphasis, and specific laboratory techniques may vary with each one. In many cases, these variations are a function of site-specific conditionstype of bedrock, climatic setting, geomorphic setting, intensity of occupation, degree of diagenetic modification, etc. Although the literature on rockshelter and cave sedimentology is growing rapidly, there is not yet an organized body of theory to provide a uniform framework for the interpretation of the sediments or for their regional correlation for this specialty, as clearly pointed out by Collcutt (1979).

\section{Scales of Sediment Study}

The sediments in an archaeological site can and should be studied on various scales - in the field, in the laboratory, and under the microscope. Detailed sediment study must begin in the field where the geologist can observe the individual strata and their components in relation to other, surrounding strata, and the complete context and setting of the site.

Sediment accumulation in a cave or rockshelter tends to be idiosyncratic. No two caves are exactly alike in their bedrock infrastructure, exposition, size, internal karstic relations, the influence of external geomorphological phenomena, etc. Isolated samples of sediment removed from the site and sent to a geologist who has never seen the site are nearly meaningless. In contrast, a geologist can, in many cases, make a very meaningful and detailed interpretation of the cave sediments from field study alone, without subsequent laboratory work. Most importantly, it is only at this stage - in the field - that sedimentary features and structures, such as laminations, cross-stratification, the sharpness or clarity of the contacts (bounding surfaces) between strata, can be fully appreciated, and lateral relations can be observed.

Laboratory analysis of sediments can also be carried out on several scales (Farrand, 1975a, 1975b, 1985, 2000). In the first place, it is essential to have a general macroscopic description of the sediments, including color, particle size and sorting, and morphology of the pebble and cobble fraction. Bulk chemical analysis follows next for calcium carbonate, phosphate, and organic matter content. These data are commonly presented in the form of a synoptic ("global") diagram that reveals how each parameter changes relative to other parameters at any point in time as well as through time from the bottom to the top of the sedimentary section. An example from Franchthi Cave (Peloponnese, Greece) is given in Figure 1. Microscopic observations of individual particles reveal the heavy mineral content and the shape and roundness of sand grains. Of increasing importance is micromorphology - the study in thin section of unconsolidated sediments that have been indurated with resins under vacuum, thus preserving the natural relations among 
grains, size sorting, in situ weathering, secondary cements, and any organic components (Courty et al., 1989).

\section{Types of Sediment}

There are three broad categories of sediments that may accumulate in a cave or rockshelter - geogenic, biogenic, and anthropogenic - and, intuitively, these may occur in any combination, from $0 \%$ to $100 \%$ of each category; but commonly there is a mixture of all three, for example, at Franchthi Cave, Greece (Farrand, 2000).

Geogenic sediments. Geogenic sediments may originate either inside the cave (endogenic) or outside (exogenic) and include the following types:

- Roof fall, either by spalling or collapse

- Disintegration of the cave bedrock by chemical and freeze-thaw weathering

- Chemical deposition of travertine (flowstone) and dripstone (stalagmites and stalactites)

- Inwashing of colluvium and soil through the cave mouth or through fissures in the cave ceiling

- Fallout of windblown (eolian) dust, either sand- or silt-sized

- Stream deposition, from inside the cave (karstic) or from external streams flowing into the cave mouth

- Beach sand or gravel, if the cave occurs along a lake or oceanic shoreline, now or in the past.

These sediments may, of course, accumulate in a cave even if there is no concurrent human occupation.

Biogenic sedimentation. Biologic components derive from animals and plants that inhabit the cave. It is rare that cave deposits are $100 \%$ or even dominantly biogenic, but they may have a conspicuous biogenic component, especially of bones and shells. Cave-dwelling animals such as bears commonly die during hibernation, leaving their bones on the cave floor. The co-occurrence of such animal bones and human artifacts is probably a result of trampling and mixing (bioturbation) subsequent to the occupation of the cave by one or the other of these groups. For example, in Yarimburgaz Cave, near Istanbul, Turkey, it is most likely that cave bears and humans lived in the cave at different seasons of the year or for longer, but alternate periods of time (Stiner et al., 1996). The same logic applies to the occurrence of owl pellets, which are those masses of hair, bones, and teeth of small animals (rodents, lizards, etc.) regurgitated by owls and other raptor birds after they have digested the flesh and skin. The raptors are unlikely to have lived in the cave while humans were occupying it, and the small animals represented in the pellets usually did not live in the cave at all but were captured somewhere outside. Bats also contribute their bones to the sediment accumulation (e.g., Tabun Cave, Israel [Jelinek et al., 1973] and Yarimburgaz Cave [Santel, 1994]). They may have lived in the deeper parts of large caves while humans were occupying the area near the cave entrance. This certainly happens today even while archaeolog- 


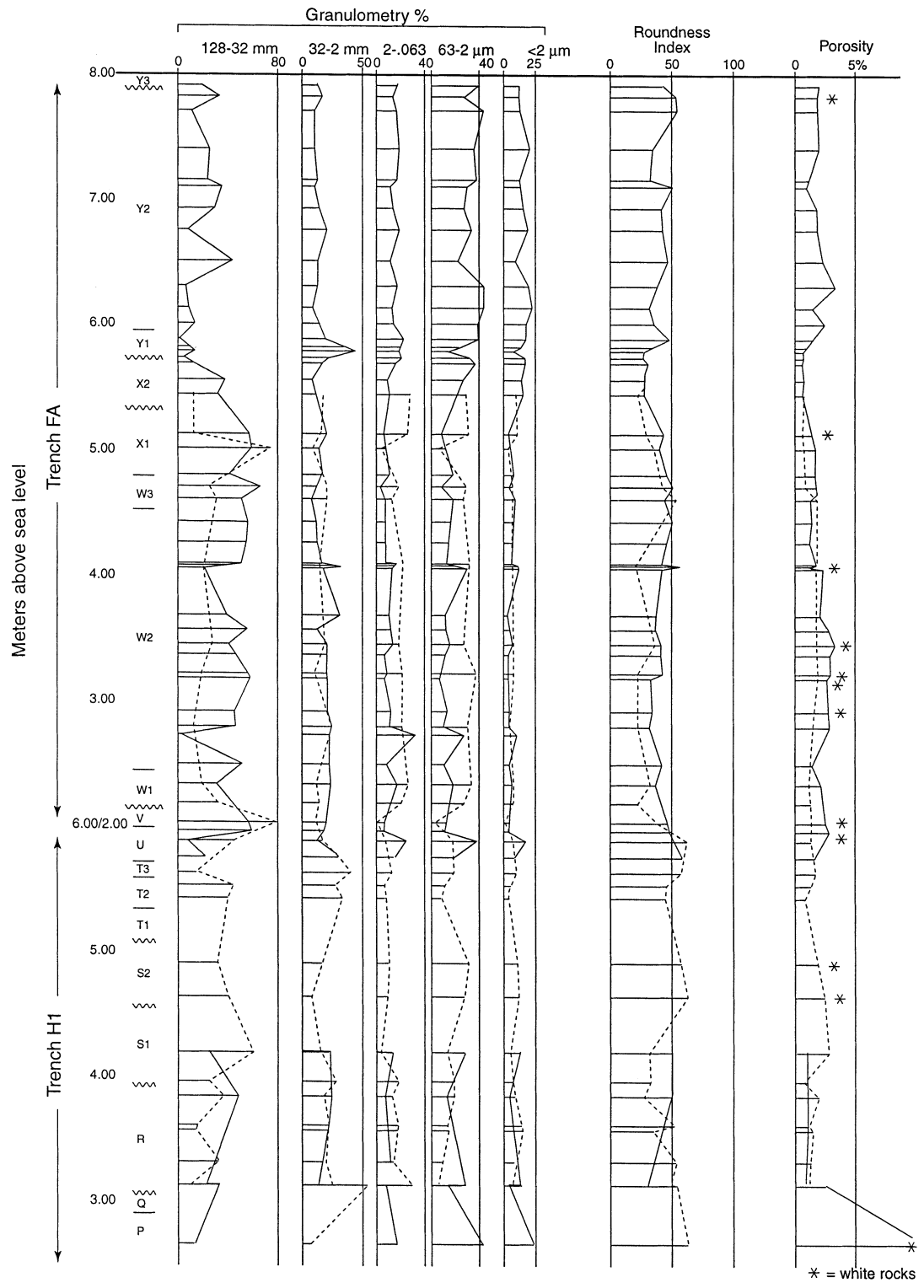

Figure 1. Global diagram of sedimentary parameters in Franchthi Cave, Greece. The Granulometry column shows the percentage of rock fragments, small pebbles and granules, sand, silt, and clay (from left to right). The Roundness Index column indicates the abundance of well-rounded rock fragments. The $\mathrm{CaCO}_{3}$ and $\mathrm{pH}$ columns reflect the effect of solution leaching of calcium carbonate from the finegrained sedimentary matrix. The Snails-Frags column show the abundance of snail shell fragments in the 1-2 mm size fraction of the matrix, and adjacent columns show the presence of snail shells with chalky surfaces, which resulted from chemical weathering on the cave floor (after Farrand, 2000). 


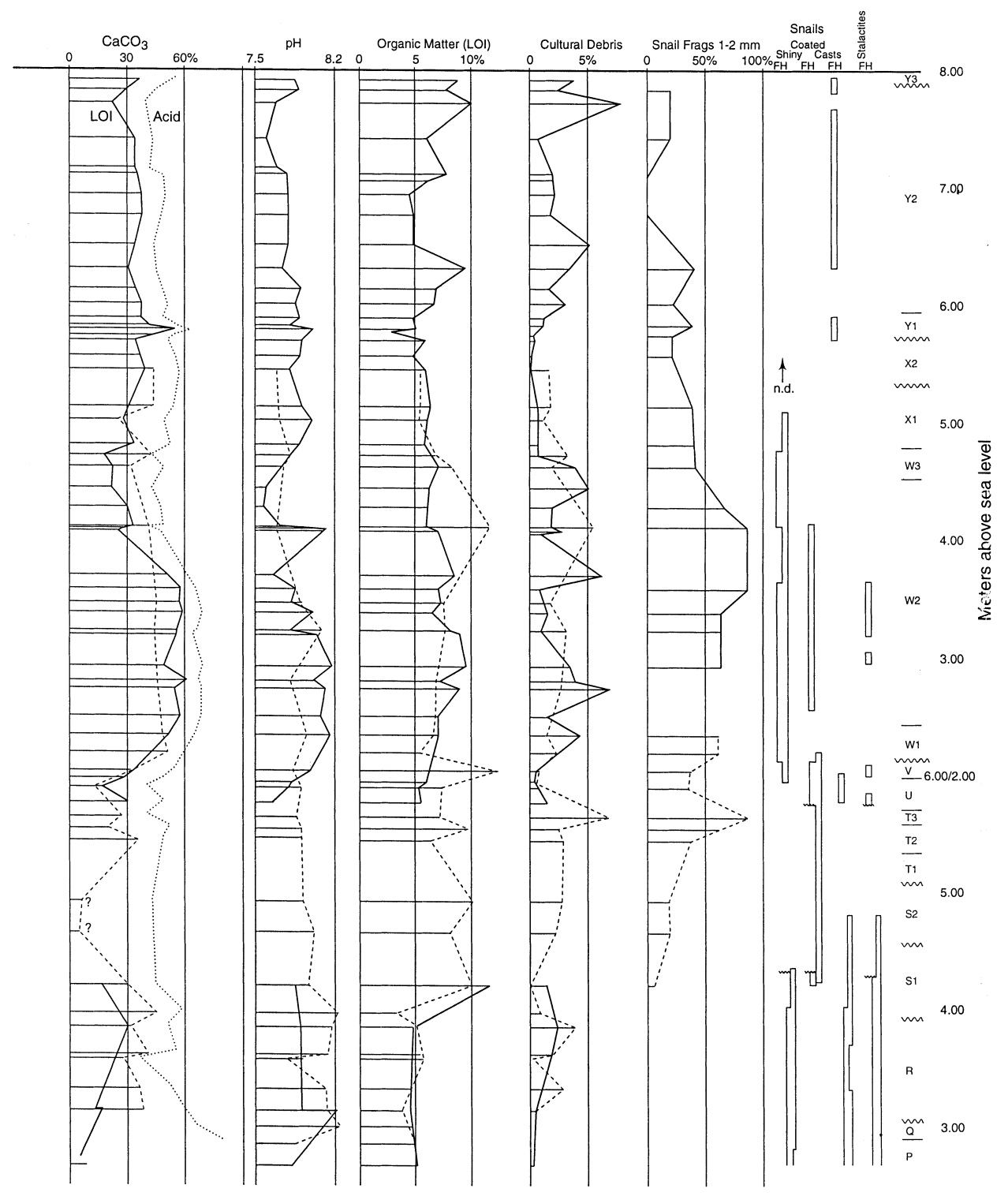

Figure 1. (Continued) 
ical excavations are going on in a cave, as we personally observed in Yarimburgaz Cave and numerous other dark caves.

In addition to bones, animals also contribute organic wastes to the sediments, such as guano from birds and bats and coprolites from mammals. In some cases, the guano is obvious by its black color and greasy texture, as in Yarimburgaz Cave (Farrand and McMahon, 1997). In the case of Tabun Cave, Israel, it is postulated that bat guano, now largely decayed and oxidized, caused the chemical destruction of bones and mineral components within an accumulating sedimentary deposit (Jelinek et al., 1973). Coprolites, moreover, may yield interesting information on the diet of the larger mammals, and, by extension, information on the environment near the cave.

Anthropogenic sediments. Anthropogenic, like biogenic, components rarely occur in isolation in a cave. They are almost always mixed to some degree with geogenic sediment, and commonly with biogenic materials as well. Nevertheless, anthropogenic components can account for a considerable percentage of the total sediment accumulation, as in the case of the Mesolithic strata in Franchthi Cave, Greece, where the sedimentation rate increased dramatically (Farrand, 2000; 2001), as described in more detail below. Butzer (1981:55) found similar situations in Cueva Morin in Cantabrian Spain. Anthropogenic contributions can result from either intentional or unintentional human acts. The cave occupants may intentionally import materials for the building of structures (rocks and wood) or for improving or leveling the cave floor (sand or soil) as in La Grotte du Lazaret, Nice, France (de Lumley, 1969). Fires are also built (for cooking or for warmth), and thus ash is added to the sediments. The ash may remain in the discrete form of a hearth, many examples of which were found in Franchthi Cave (Farrand, 2000), or it may be scattered and mixed with other kinds of sediment. Moreover, the ash may be transformed by post-depositional processes, but its residue can still be recognized (Schiegl et al., 1996).

People also bring in food stuff that may leave relatively durable debris behind, especially animal and fish bones and shells of land snails or marine shellfish. In some cases, this food waste accumulates in discrete piles (middens) that include only a small fraction of geogenic matrix, such as land snail middens in Franchthi Cave. Such a case is illustrated in the "Snails-Frags" column in Figure 1, which shows the dominance of snail shell fragments in the 1-2 mm size class (coarse sand size). In other cases, the bones and shells may be widely scattered throughout the geogenic sediments, as is the case for marine shells in Franchthi Cave (Farrand, 2000).

In some caves, or in certain strata in a given cave, there may be a considerable contribution of sediment unintentionally imported by humans. Much of this component is brought in as mud on people's feet and dirt on their clothing, especially fur garments. Also vegetation brought into the cave (tree branches, sea weed, etc.) may have dirt and soil attached to it. It appears that such contributions account for a large fraction of the sediment in Mesolithic strata in Franchthi Cave, judging from the abundance of sand-sized minerals exotic to the cave bedrock, on one 
hand, and from the very rapid rate of sediment accumulation, on the other. These strata also include much intentional anthropogenic sediment, especially snail shells and large fish bones, all of which increased the sedimentation rate to as much as $250 \mathrm{~cm}$ per 100 years in Stratum W, compared to only 4-7 cm per 100 years in the preceding Upper Paleolithic strata and about $17-23 \mathrm{~cm}$ per 100 years in succeeding Neolithic layers (Figure 2) (Farrand, 1988, 1993, 2000). Further discussion of sedimentation rates is given below.

In addition to contributing sediment to the cave floor, the inhabitants commonly modify or remove completely the sediment that had previously accumulated. Pits may be dug for the emplacement of hearths or burials, and the sediment removed may be deposited elsewhere on the cave floor. On a larger scale, "house cleaning" by prehistoric occupants may evacuate a considerable amount of previously deposited sediment. For example, at the Abri Pataud (Dordogne, France), the people living at the time of Level 5 removed sediment under the overhanging rockshelter where they were living and threw it out on the terrace in front of the site (Level 5: Front, thickness $75 \mathrm{~cm}$ ). This created a so-called "reversed stratigraphy" in Level 5: Front as older artifacts came to be redeposited over younger ones during the progressive removal from the rear of the shelter. The result was a depression along the back wall of the rockshelter, at least $75 \mathrm{~cm}$ deep (Level 5: Rear), that truncated several older strata (Farrand, 1975a, 1975b; Movius, 1975).

\section{Discussion}

Clearly it is a major challenge for the sedimentologist to disentangle the various proveniences of different kinds of sedimentary components that accumulate simultaneously in a single stratum. In some sites, there may be individual strata that are composed of sediments of a single provenience, such as a layer of pure windblown sand (e.g., Layer F at Tabun Cave, Israel; Jelinek et al., 1973). This occurrence provides a criterion for evaluating wind-transported components in other layers of mixed provenience in the same site. Exogenic sediments can commonly be identified by exotic or allochthonous minerals that cannot possibly originate from the cave bedrock. A clear example comes from the Abri Pataud (Figure 3), where in certain strata the sandy matrix between the larger rock fragments contains an assemblage of heavy minerals, including hornblende, garnet, and epidote, that do not occur in the bedrock of the shelter wall. Heavy minerals are grains of certain minerals that have a higher specific gravity than the most common minerals, such as quartz, calcite, mica, and feldspar, in sedimentary deposits, and they tend to be darker in color. These minerals, along with much quartz sand, must have blown into the shelter from the adjacent river floodplain (Farrand, 1975a, 1975b, 1995). However, some sedimentary components may be ambiguous; for example, some mammalian bones might have been brought in by humans, or by animal predators, or even have been washed in by geological processes, or they may represent animals that lived in the cave. In any case, an understanding of the gamut of possible processes that contributed to the cave sediment is essential for deciphering the sedimentary and environmental history of the site. 


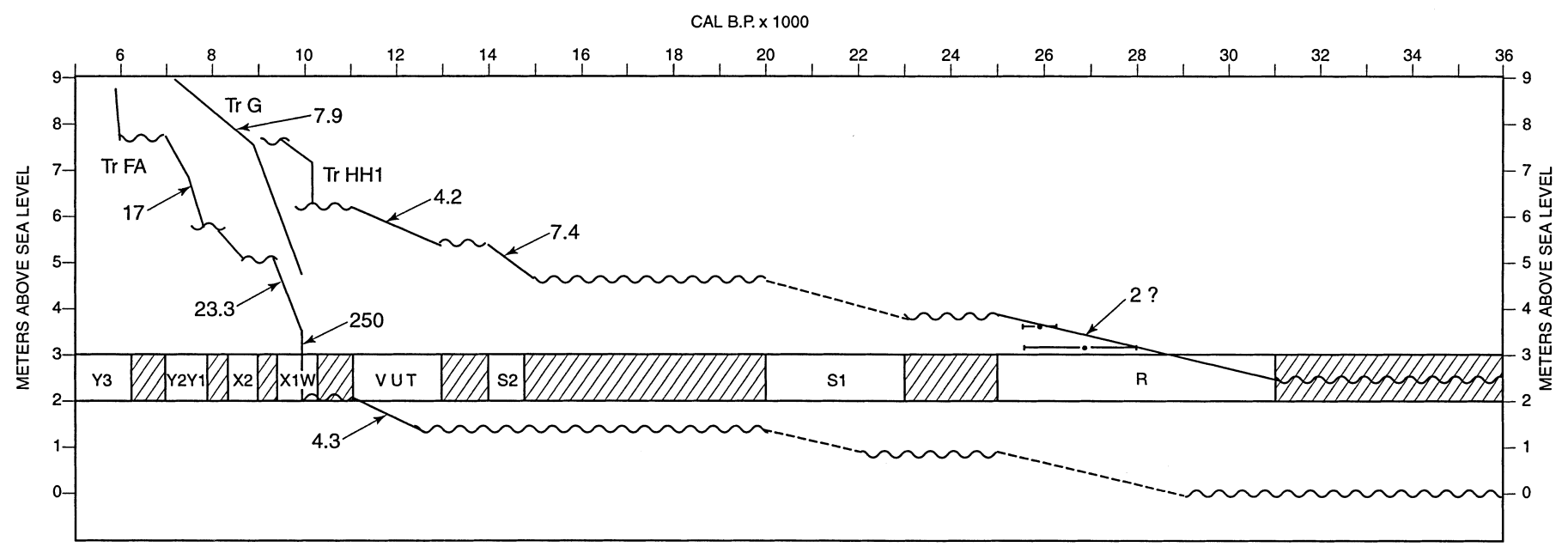

Figure 2. Sedimentation rates for Trenches FA and HH1 in Franchthi Cave, Greece, based on 50 radiocarbon ages on charcoal (Farrand, 2000). Horizontal wavy lines indicate time gaps based on these dates and sedimentological information, and they also appear in Figures 1 and 5. Dashed lines are assumed interpretations. Rates vary from $4-7 \mathrm{~cm} / 100 \mathrm{yr}$ prior to $12,000 \mathrm{cal}$ yr B.P. to as much as $250 \mathrm{~cm} / 100 \mathrm{yr}$ around 10,000 cal yr B.P. Calibrations provided by Murry Tamers (Beta Analytic, Inc.) on the basis of the Trondheim protocol in Radiocarbon 28 (2B), 1986. 


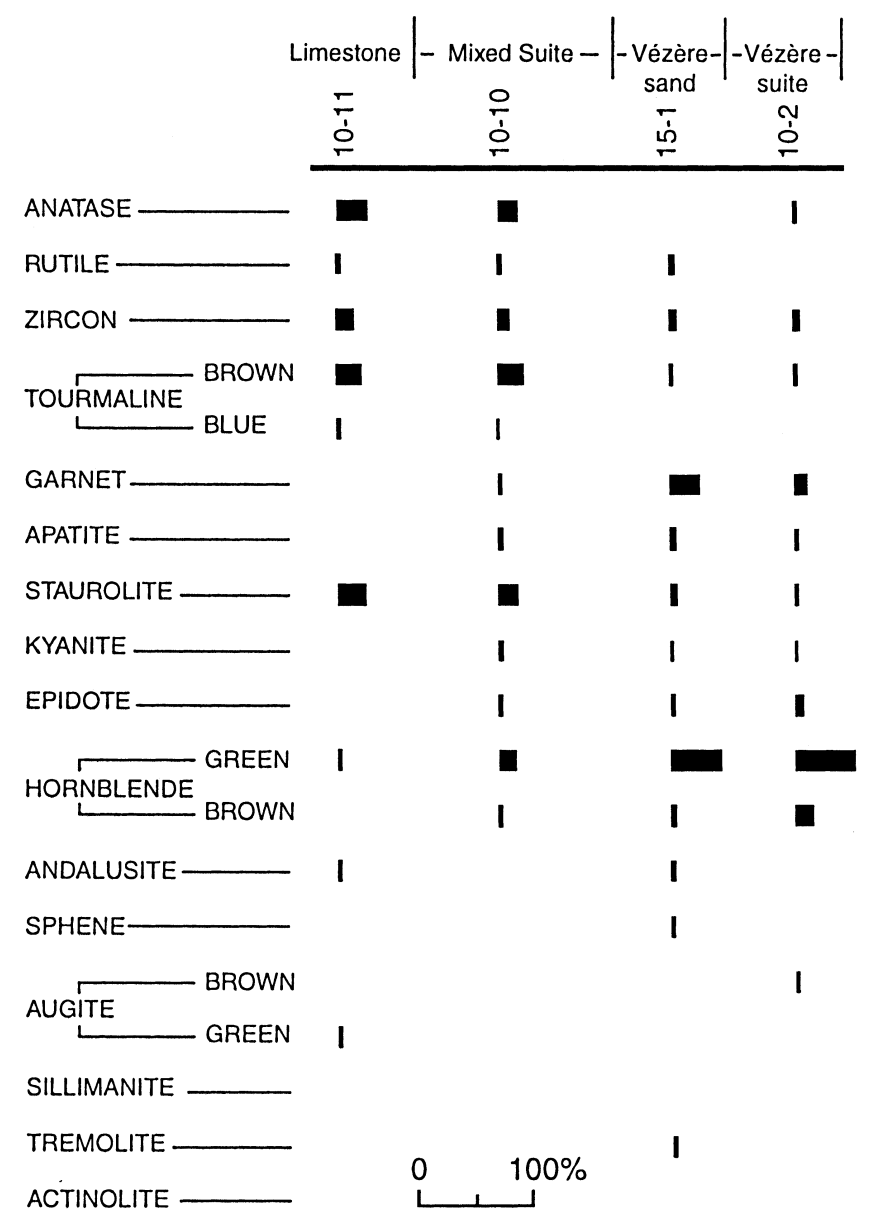

Figure 3. Variations in heavy mineral suites in the sandy matrix of representative samples from the Abri Pataud, Dordogne, France. The heavy minerals in sample 10-11 are present in the bedrock of the cave wall, and those in sample 15-1 occur in the Vézère river sands outside the cave. Sample 10-2 from stratum "Eboulis 10-11" in the rockshelter is nearly identical with the Vézère sands, indicating that the sand was blown into the shelter from the floodplain. Sample 10-10 from stratum "Eboulis 5-6," on the other hand, shows a suite of heavy minerals representing a mixture of minerals from bedrock and those from the river (modified from Farrand, 1975a, 1975b, 1995).

\section{SAMPLING TECHNIQUES}

Collecting samples for sediment study is a function of several pragmatic factors - site size, duration of the total study, distance to the laboratory where analysis will be done, money for shipping samples, coarseness of the sediments - as well as a function of research goals. Some sites may be sampled in great detail, while others may be sampled selectively for specialized studies. 
Many cave and rockshelter sites are filled with rather coarse sediments as a result of breakdown of the cave bedrock, necessitating the collection of rather large samples that are statistically representative. Therefore, a decision must be made about the upper limit of clasts that will be collected. The French school (Bonifay, 1962; Laville et al., 1980) chose $100 \mathrm{~mm}$ for the maximum size to be analyzed in the laboratory. I modified this choice (Farrand, 2000:60) slightly to $128 \mathrm{~mm}$, which is exactly -7.0 phi on the sedimentologists' logarithmic scale, in order to plot granulometric results consistently at whole phi intervals. Clasts $>128 \mathrm{~mm}$ can be observed in the field and usually are shown on section drawings. In any case, samples with many clasts in the $32-128 \mathrm{~mm}$ range must be large to be statistically valid. Ten to $20 \mathrm{~kg}$ per sample was required in the very rocky sediments at the Abri Pataud (Farrand, 1975b, 1995), but, in other caves with finer sediment, samples of only 1$2 \mathrm{~kg}$ are sufficient; for example, in Tabun Cave, Israel, much of the sediment is windblown sand and silt (Jelinek et al., 1973).

Another choice to be made is the number of localities to be sampled in a given site. If, upon field inspection, the sediments in all the excavated areas of the site appear relatively uniform, one sampling column may be reasonably representative. This idea was tested at the Abri Pataud (Farrand, 1975b). If variability throughout the site is apparent, at least one column should be sampled from each excavation area or trench.

In a given sampling column, usually on the wall of a trench that has been recently excavated, the usual strategy is to take at least one sample from each lithostratigraphic layer that appears visibly different from those layers above and below. These may or may not be coincident with the excavation levels or spits designated by the archaeologists. An effort should be made to limit the vertical thickness of each sample to $5-10 \mathrm{~cm}$, but this will depend on the coarseness of the sediments.

\section{THE LABORATORY STUDY OF CAVE AND ROCKSHELTER SEDIMENTS}

Once the sediments have been examined in the field, the laboratory phase can begin. As mentioned above, basic description of the color, granulometry, pebble morphology, mineralogy, and bulk chemical properties are analyzed by various techniques, for example, those outlined by Farrand (1975a, 1975b, 1985, 1995, 2000) and by Laville et al. (1980). The results, then, are commonly presented in the form of a global stratigraphic diagram, as in Figure 1. Other examples can be found in Laville et al. (1980).

Inspection of the global diagram can identify simultaneous changes in multiple parameters; for example, certain levels with a reduction of overall particle size, increased rounding of the rock fraction, decreased $\mathrm{CaCO}_{3}$ and $\mathrm{pH}$, and chalky surfaces on pebbles and cobbles (e.g., Stratum U in Figure 1) point to a time when sediment input was strongly reduced or ceased entirely, accompanied by chemical weathering of the exposed sedimentary surface, and possibly cessation of human occupation of the cave. A corollary of this conclusion is that during the weathering 
interval little or no sediment was accumulating, and therefore there is a time gap (hiatus) prior to the resumption of sedimentation. Fully developed pedogenesis is uncommon in caves because of limited exposure to the external atmosphere and the lack of vegetation inside a cave. Time gaps can also be identified by visibly eroded surfaces observed in the excavations, by offsets in a series of radiometrically dated levels (Figure 2), or by discontinuities in artifact or faunal sequences (Farrand, 2000). Such gaps can represent a considerable percentage of the total time span of a given site; in Franchthi Cave (Figure 4) at least 50\% of the interval between 26,850 and 6000 cal yr B.P. is not represented by any sediments in the excavated parts of the cave. Unfortunately for the cultural history of the site, two important gaps at Franchthi occur at the critical Paleolithic/Mesolithic and Mesolithic/Neolithic boundaries, which means that the question of transition or replacement of cultural traditions cannot be addressed directly. For the most part, however, such time gaps are not easy to recognize in the field during excavation, and one may have the false impression that sedimentation at the site was continuous through time, which was probably never the case for a deeply stratified site (see Campy and Chaline, 1993).

\section{SEDIMENT ACCUMULATION RATE}

Given a sufficient number of radiocarbon dates and the recognition of hiatuses in sediment accumulation, one can plot a sedimentation rate curve, such as the one from Franchthi Cave (Figure 2). If the input is sufficiently detailed, one can estimate the rate of sedimentation throughout the total duration of use of the cave. In some cases, there was considerable variation - of at least two orders of magnitude within a few thousand years. A spectacular case is Franchthi Cave where the rate during Upper Paleolithic times was about $4 \mathrm{~cm} / 100 \mathrm{yr}$, and the rate increased to $250 \mathrm{~cm} / 100 \mathrm{yr}$ during Mesolithic time. Only a few other sites have sufficient ${ }^{14} \mathrm{C}$ ages on which to base such calculations. Cueva el Mirón in Cantabrian, Spain has rates of about $3 \mathrm{~cm} / 100 \mathrm{yr}$ in both Magdalenian and Neolithic/Bronze Age levels (Straus et al., this issue). The Abri Pataud in France, although not Mediterranean, has an average rate of $5.5 \mathrm{~cm} / 100 \mathrm{yr}$ for the entire sedimentary fill, but some sections have rates up to $10-18 \mathrm{~cm} / 100 \mathrm{yr}$ (Farrand, 1975b: 51).

These variations may have resulted from changes in either geogenic or anthropogenic sedimentation, or both. The variations are worthy of serious consideration when evaluating the intensity of use of the site as a function of the density of artifacts or fauna. For example, the density of artifacts in a certain 20-cm-thick stratum may be ten times as great as the density in another stratum of the same thickness, but the second stratum may have accumulated ten times as fast as the first stratum. Thus, the number of artifacts accumulating per unit time would have been identical in the two cases.

\section{STRATIGRAPHIC CORRELATION}

Commonly, the excavated areas or trenches in a cave or rockshelter are disjunct from one another, and thus the sedimentary sequence in each separate trench must 
FA

$\mathrm{HH} 1$

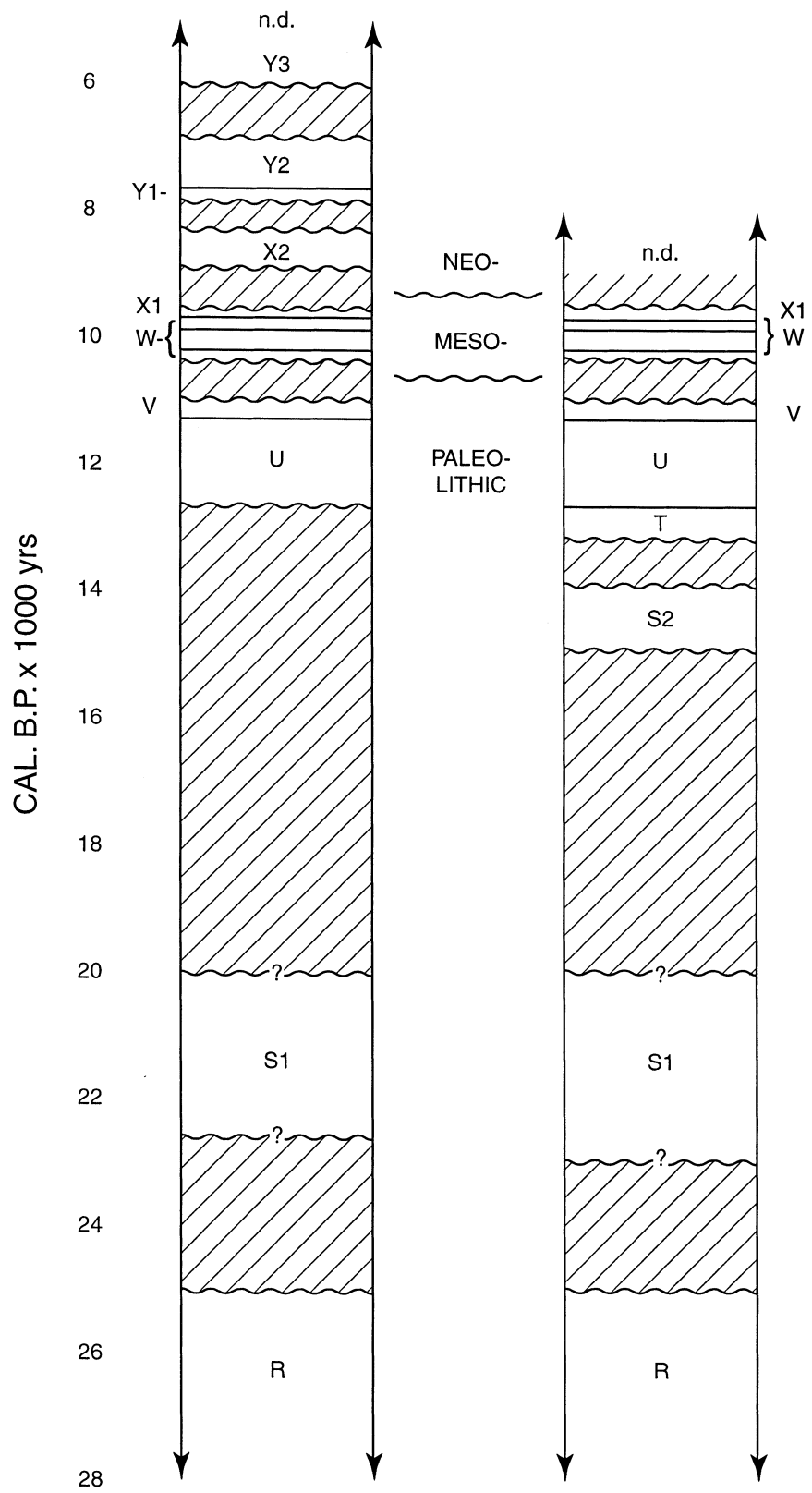

Figure 4. Lithostratigraphic units in Trenches FA and HH1 in Franchthi Cave, Greece, plotted against an absolute time scale in calibrated radiocarbon years (see Figure 2), illustrating the time gaps in both trenches (diagonal ruled lines). The lithostratigraphic units (Z, Y3, Y2, Y1, ...) are the same as in Figures 1 and 2 (after Farrand, 2000). 
be correlated by some means with those sequences in other trenches. This task is commonly complicated because the pattern of sedimentation in different parts of the cave may be different - for example, dominantly roof fall in one area, running water in another, and eolian input in still another, but all at the same time.

Correlation by means of artifacts may be misleading because of different activity areas or inconclusive because the sedimentary stratigraphic units (lithostratigraphy) may be finer than the artifact stratigraphy (ethnostratigraphy). Faunal or ethnobotanical (biostratigraphic) correlation may fail for the same reasons. Similarly, radiocarbon (or other) radiometric dating may be lacking in critical strata or too coarse, especially because of the standard deviations associated with such dates, to allow correlation of individual sedimentary layers.

Therefore, the characteristics of the sediments themselves and the recognition of hiatuses based on weathering criteria must be utilized in establishing detailed correlation from trench to trench. Radiocarbon ages and faunal and artifact distributions can be helpful adjuncts, but not the primary means of correlation. Figure 5 shows a generalized example from Franchthi Cave where the lines correlating the two trenches connect discrete stony layers (Xl and V), weathered surfaces marked by chalky white altered rocks (U and S2), and a singular tephra (volcanic ash) layer (Q).

\section{The Changing Configuration of a Cave or Rockshelter}

The size and shape of a cave or rockshelter may appear static, but over periods of a few thousand to a few tens of thousands of years, there may be considerable change. Rockshelters, in particular, evolve relatively rapidly, simultaneously with their sedimentary infilling, so that they may ultimately disappear from the landscape. Incipient rockshelters may be only small cavities at the base of a cliff, but as time proceeds the cavity grows larger and deeper, and the overhanging brow provides increasing protection from the weather. Ultimately, however, the undercut cavity below the brow becomes so deep that the brow becomes structurally unstable and begins to collapse, thus, reducing the size of the shelter, as illustrated in Laville et al. (1980). Thus, at certain times in the past, the protected area under the shelter may have been considerably larger than what we see today (i.e., during excavation). The drip line may have been well out in front of the present shelter on what is now an open-air talus slope. As the brow collapses, the cavity beneath it is filled with sediment, so that the shelter may finally be completely filled. This process was reconstructed at the Abri Pataud, where the stratigraphic filling of the shelter revealed the timing of the large rock falls from the brow and ceiling. A composite profile of the Abri Pataud (Figure 6) shows the evolution of the shelter from about 34,000 yr B.P. until about 22,000 yr B.P. At the time of Level 3, the overhang had its greatest extent, and the shelter was at its maximum size.

Deep caves, too, may have had different configurations in the prehistoric past. At Franchthi Cave a major ceiling collapse caused major changes. Near the end of the Neolithic habitation, a large section of the cave roof collapsed into the cave, 


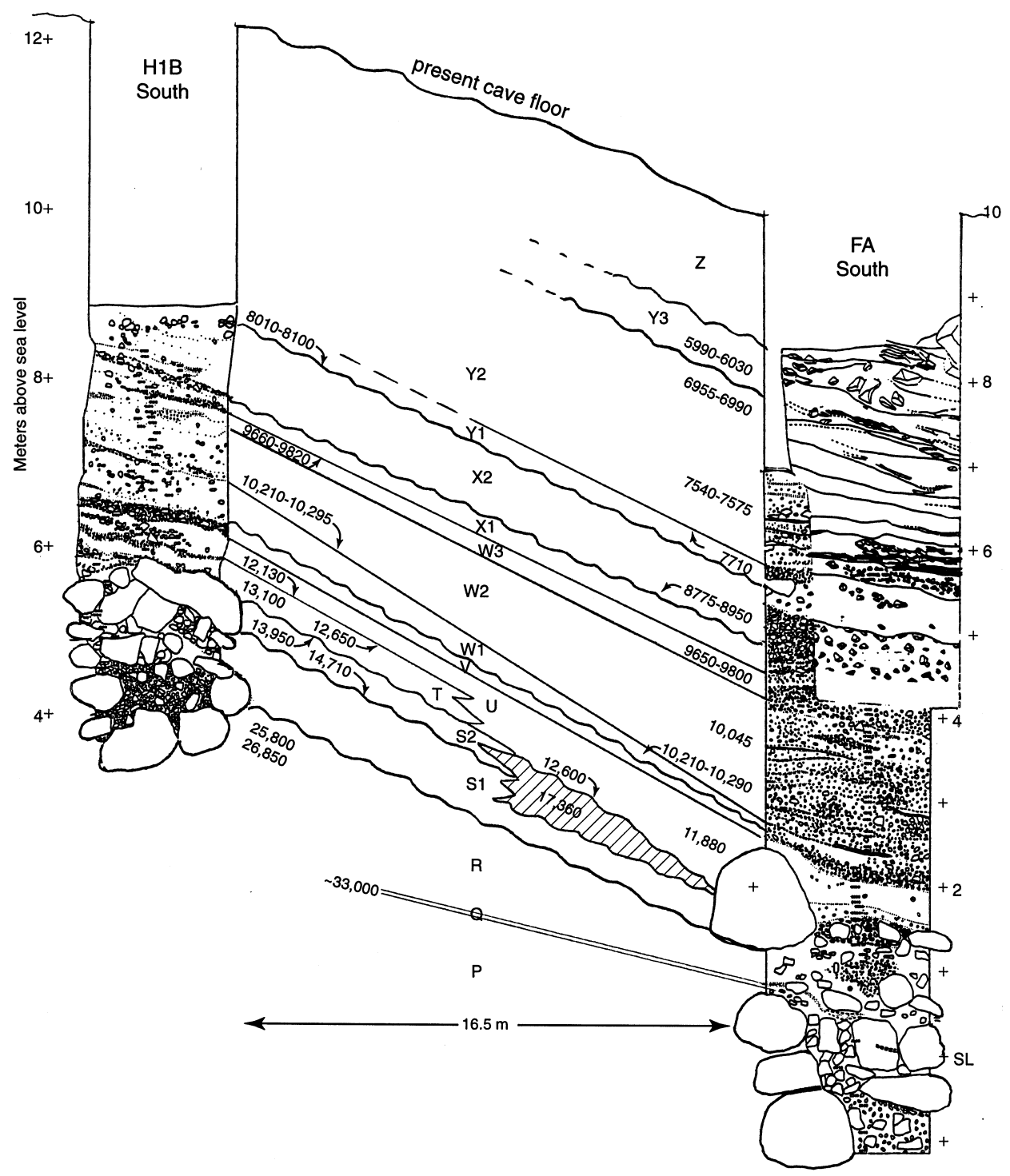

Figure 5. An example of correlation between two trenches based on sedimentological characteristics. In particular, rocky layers $\mathrm{X} 1$ and $\mathrm{V}$, and the volcanic tephra $\mathrm{Q}$ were especially useful in this correlation. Also, Strata U and S1 with chalky white rocks, indicating episodes of weathering, established linkages between the trenches. The ${ }^{14} \mathrm{C}$ dates are calibrated as in Figure 2 (after Farrand, 2000). 


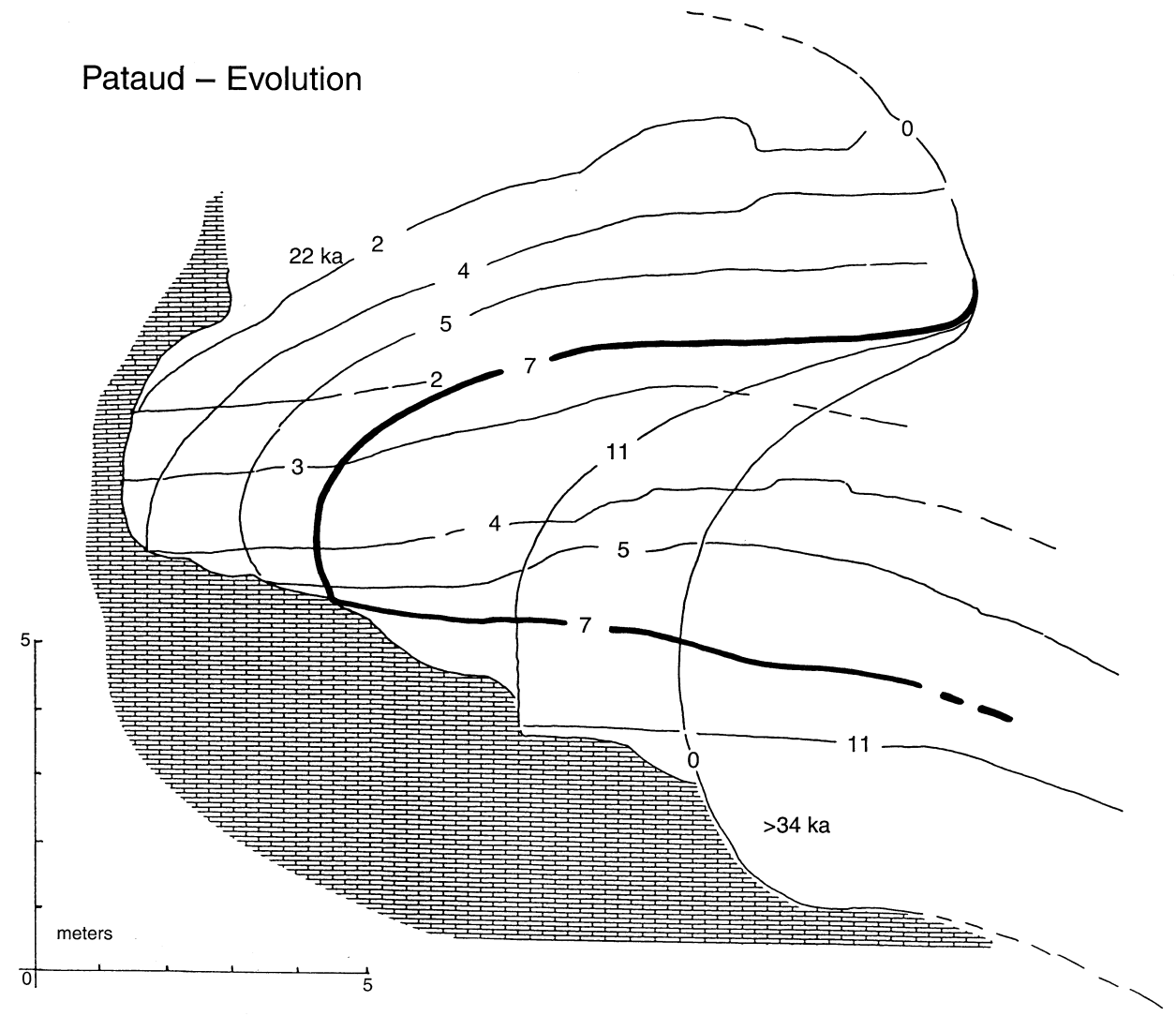

Figure 6. Reconstructed sagittal profiles through the Abri Pataud, France. The numbered lines show the position of the floor, backwall, and ceiling of the shelter at times of different occupations from 34,000 to 22,000 yr B.P. Line 0 is the presumed original configuration of the initial bedrock niche; numbers $2-11$ are reconstructed profiles at the times of given occupations, with 11 being the oldest and 2 the youngest. The configuration at the time of occupation 7 is emphasized by a heavier line simply to make it easier to read the diagram. As the floor was gradually filled with sediment, the shelter was progressively enlarged, with a greater overhang, up to the time of occupation 3 . After that time, successive collapses of the brow reduced the sheltered area to its present configuration shown by the solid pattern.

leaving a wide "window" open to the sky, thus admitting abundant daylight into the previously dark cave. The pile of collapsed rocks buried the living floor of Late Neolithic times under tons of rock debris as much as $20 \mathrm{~m}$ thick, totally changing the living space within the cave (Farrand, 2000: Figure 3.2).

In another instance, at Tabun Cave in Israel, the upper part of the sedimentary sequence is quite different from the lower two-thirds (Jelinek et al., 1973). The upper strata are composed of heavy red clayey sediment with abundant rock frag- 
ments derived from the walls of the cave. At present, there is a 5-m-wide "chimney" in the cave ceiling, open to the sky. The red clayey sediment is clearly red soil derived from terra rossa soils that washed into the cave from above, and the large limestone rocks were detached from the walls and ceiling as the chimney opened progressively. The absence of both red clay and limestone rocks in the lower sediments is interpreted as evidence that the chimney was not open during the tens of thousands of years represented by the lower sediments. Thus, the inner chamber of the cave would have been darker and more sheltered in those earlier times.

\section{ENVIRONMENTAL AND CLIMATIC INTERPRETATION}

Up to this point, this discussion has dealt with the descriptive phase of sediment study. The descriptions are an essential component of site study and very important as a means of communicating to others the character of the sedimentary sequence exposed during excavation. It is vital that these descriptions be as accurate and detailed as possible because, as is well known, an archaeological site is destroyed in the process of excavation. Also, in many cases, the trenches are filled in the close of the excavations and cannot be revisited or re-examined without great difficulty, if at all.

From another point of view, the character of the sediment - its lithology, particle size, provenience of mineral components, kinds of stratification, degree and kinds of alteration, etc. - can lead to the interpretation of the environment, both inside and outside the cave, under which the sediment accumulated and in favorable circumstances can lead to paleoclimatic reconstruction (Farrand, 1975a, 1975b; Laville et al., 1980). An example of the use of such parameters in connection with information external to the site, such as pollen and sea-level data, is given in Farrand (1979) for Near Eastern sites.

\section{Polymodality}

As stated above, the sediments in a rockshelter or cave commonly result from simultaneous inputs from two or more sources - rockfall, wind action, human activity, and so forth. As a means to sorting out these different influences, I have long espoused the use of granulometric histograms showing the particle-size distribution of the total sediment (Farrand, 1975a, 1975b). From an upper limit of $128 \mathrm{~mm}$ (or -7 phi), which is arbitrary but practical, down to fine clay, such histograms commonly show multiple peaks or modes (Figure 7). Each mode demands an explanation for its presence, that is, identification of the mode with a sedimentary process. More than one mode may be associated with a single process, or each mode may relate to a different process. In the case of Franchthi Cave (Figure 7), the sequence evidences:

- A very coarse mode that reflects breakdown of the cave ceiling

- A mode in fine gravel (16-2 mm) resulting from sediments imported into the cave intentionally or not by humans 


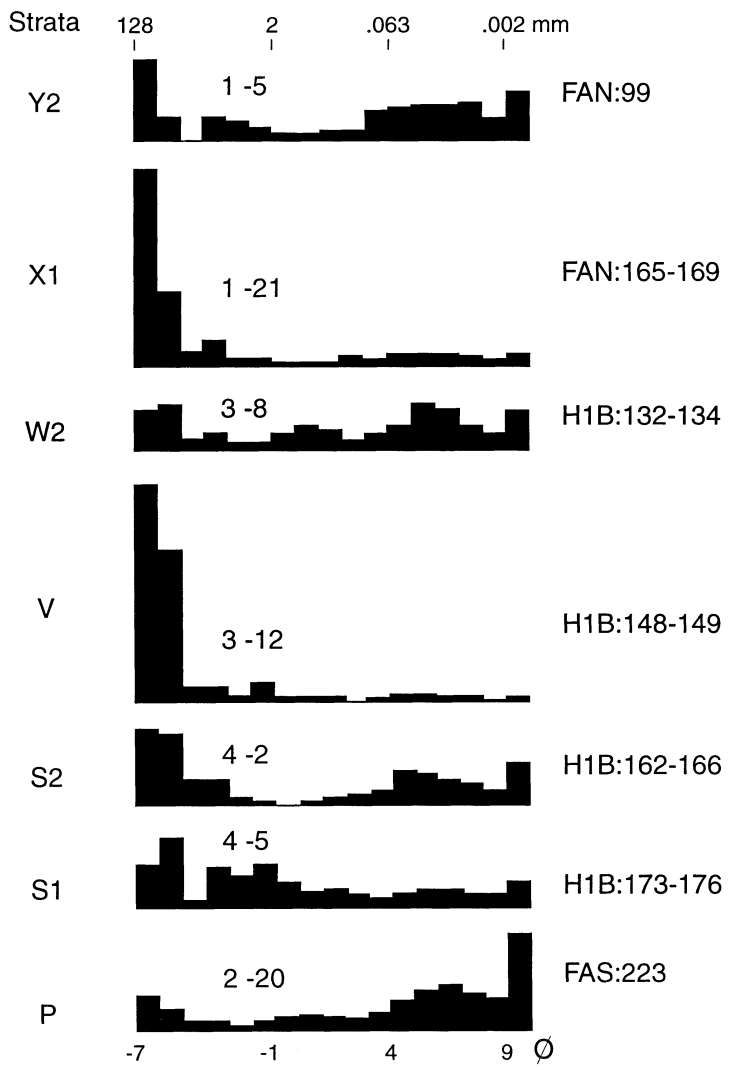

\section{FRANCHTHI}

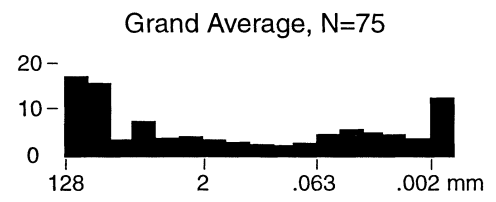

Percentage of Samples with

Distinct Mode in Given $\varnothing$ Interval

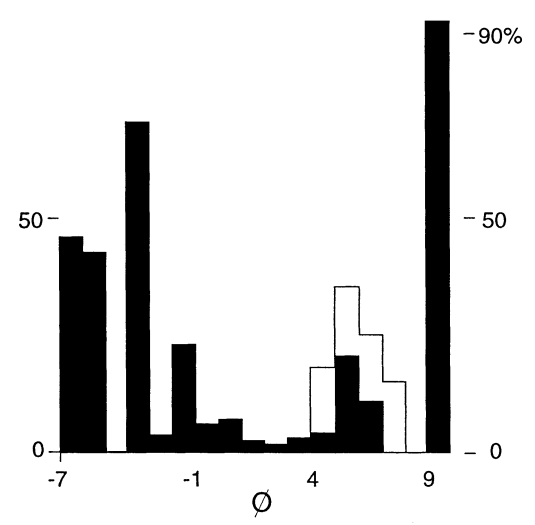

Figure 7. Typical granulometric histograms of selected strata in Franchthi Cave, Greece. Also shown is a histogram (upper right) of all 75 histograms averaged together (on a millimeter scale) and a histogram showing the percentage of samples that include a peak in each of the five prominent modes (from Farrand, 2000). 
- A diffuse sand mode (but prominent is Stratum W2) mostly introduced from beach deposits outside the cave by human activities

- A silt mode probably blown in from the coastal plain, given its exotic mineralogy

- A clay mode reflecting input of red soil through cracks and fissures in the cave roof (Farrand, 2000).

Such interpretation is just a starting point, and each explanation should be verified by other analyses. Micromorphology would be helpful especially for the finegrained components (Courty et al., 1989), as would electron microscopy for examining mineral grain surfaces (Krinsley, 1973).

\section{Freeze-Thaw Activity}

In the case of regions where the climate, present or past, is characterized by temperatures that fall below $-5^{\circ} \mathrm{C}$, freezing and thawing of bedrock or rock debris can cause the rock material to fracture into smaller, angular fragments. Such angular debris is characteristic of many rockshelters and caves occupied during the times of past glaciations in north temperate latitudes (Laville et al., 1980) including the uplands of the northern Mediterranean rim (Bailey and Woodward, 1997). Variations in the size, shape, angularity, and amount of fine matrix between the frost fragments can be interpreted in terms of the varying impact of freeze-thaw climates of the past. There are differences of opinion, however, about the interpretation of frost-derived fragments. In the past, it was commonly thought that more large frost fragments indicated a more intense frost climate (Laville et al., 1980; Farrand, 1995). However, experimentation on freezing and thawing of rocks under controlled conditions shows that it is the frequency of freeze-thaw cycles that is important. The more freeze-thaw cycles that a rock is subjected to, the smaller the frost fragments become as the larger fragments are successively broken down to smaller ones (Farrand, 1975a, 1975b; Guillien and Lautridou, 1970). Thus, abundance of large frost fragments presupposes fewer frost cycles.

Angular rock fragments may be produced by other mechanisms, however, and their presence in some sites has been misinterpreted as an indication of frost climate. Farrand (1979, 1981) reports angular rock debris in several prehistoric sites - Franchthi Cave, Qafzeh Cave (Nazareth, Israel), Ksar 'Aqil rockshelter (Lebanon), and el-Khiam (Judean Desert) - that have never experienced freezing conditions (of at least $-5^{\circ} \mathrm{C}$ ), according to independent climatic indicators. Therefore, in these cases, the interpretation of freezing climates greatly exaggerates past climatic change. An alternate mechanism for the production of angular rock fragments is hydration weathering, that is, the frequent wetting and drying of a rock surface (White, 1976).

\section{Heavy Minerals}

Heavy minerals were discussed above in connection with sediment provenience (see Figure 3), but they can be useful in other ways. At Tabun Cave in Israel there 
is a drastic shift in the heavy mineral composition from the lower two-thirds to the upper third of the sedimentary fill (Jelinek et al., 1973). The upper third contains a full complement of the heavy minerals found in the coastal dune sands on the adjacent coastal plain. In the lower section, which is largely sand blown from the same coastal area, certain heavy minerals are conspicuously absent, especially hornblende and epidote, which are particularly susceptible to chemical weathering. This is some of the evidence for a major unconformity between these two stratigraphic sections, implying also a different weathering regime above and below (Farrand, 1994).

\section{Recognition of Hiatuses}

Periods of weathering of the accumulated sediments can be interpreted from color, roundness of rock fragments, clay content, obscured stratification, decreased $\mathrm{CaCO}_{3}$ content, lowered $\mathrm{pH}$ (see Strata W3/upper W2 and Strata V/U in Figure 1), and, in some cases, changes in heavy mineral suites, as just mentioned above. Other features can be seen in micromorphological studies, such as clay skins (cutans), differential weathering of mineral grains, internal textures, and the like (Courty et al., 1989). Dark brown or reddish brown (oxidized) colors in a sedimentary sequence that is generally light-colored is one of the first aspects to indicate a weathered horizon. Secondly, enrichment in clay content relative to overlying and underlying strata is evidence of pedogenic alteration of primary minerals into clay minerals (Stratum 3/4:Red at Abri Pataud; Farrand, 1975a, 1975b). Third, solution of fine-grained calcareous sediment occurs when normal rain water, which is slightly acid, filters through the strata. At the same time, the acid action of the water will round the originally sharp angles and corners of larger rock fragments and may leave chalky residues on rock surfaces. These processes of oxidation, clay weathering, and acid solution, along with bioturbation by plant roots and burrowing animals, tend to obscure the original stratification.

All of these alterations will occur if the surface of the sedimentary sequence is stable, that is, no additional sedimentation is occurring and no physical erosion is taking place for a period of time sufficient for such weathering to take place. The degree of alteration and soil formation is a function of both the duration of surface stability and the intensity of the weathering climate, and they will be favored in localities closest to the cave entrance or drip line. Thus, a hiatus occurs in the sedimentary sequence that is equivalent to the time necessary for the recognized weathering to take place, a period of a few centuries at least. The corollary of such a conclusion is that some period of time will not be represented by sediment accumulation in the site. For Franchthi Cave, see Figure 4. Other Mediterranean sites with hiatuses of thousands to ten thousands of years are described in Farrand (1979), including Tabun, Qafzeh, and Sefunim caves in Israel and Ksar 'Aqil rockshelter in Lebanon. 


\section{FINAL REMARKS}

The contributions of geoarchaeology to the reconstruction of prehistoric life, particularly in rockshelters and caves, can come at many points in the excavation and study of a site. Even before going into the field, the geoarchaeologist should help in the planning of the field operations so that the needs of each specialist are properly anticipated. It is important to avoid conflicts or oversights where the data desired by one specialist are compromised by data collection of another.

Geoarchaeological research must begin in the field at the archaeological site. Field examination of the excavations and the surrounding area will lead to a plan for sediment sampling and constitutes the first phase of description of the site sediments. Characterization of the sediments by means of laboratory analysis and subsequent microscopic examination will complete the descriptive phase. Concurrently, the geoarchaeologist must work with the archaeologists to establish the stratigraphic context, trench-to-trench correlation, and chronology.

Finally, the interpretative phase involves sorting out the various processes that contributed to the sediment accumulation-geogenic, biogenic, and anthropogenic - and identifying the sedimentation processes or environments. Close collaboration with the archaeologists and floral and faunal specialists as equal partners is essential in order to bring all the information gathered at the site into the final interpretation. It is important for all to realize that the kinds of sedimentary processes at the site may have an influence on the kinds of cultural activities that could be practiced and on the degree of preservation of the cultural record, just as the kinds of cultural activities may have a strong influence on the sedimentary record.

\section{REFERENCES}

Bailey, G.N., \& Woodward, J.C. (1997). The Klithi deposits: Sedimentology, stratigraphy and chronology. In G.N. Bailey (Ed.), Klithi Palaeolithic settlement and Quaternary landscapes in Northwest Greece. Volume 1: Excavation and intra-site analysis at Klithi (pp. 61-94). Cambridge, UK: McDonald Institute for Archaeological Research.

Bonifay, E. (1962). Les terrains Quaternaires dans le Sud-Est de la France. Bordeaux: Imprimeries Delmas.

Butzer, K.W. (1981). Cave sediments, Upper Pleistocene stratigraphy and Mousterian facies in Cantabrian Spain. Journal of Archaeological Science, 8, 133-183.

Campy, M., \& Chaline, J. (1993). Missing records and depositional breaks in French late Pleistocene cave sediments. Quaternary Research, 40, 318-331.

Collcutt, S.N. (1979). The analysis of Quaternary cave sediments. World Archaeology, 10, 290-301.

Courty, M.A., Goldberg, P., \& Macphail, R. (1989). Soils and micromorphology in archaeology. Cambridge: Cambridge University Press.

de Lumley, H. (1969). Une cabane acheuléenne dans la Grotte du Lazaret (Nice), Mémoires de la Société Préhistorique Française, Tome 7. Paris: Centre Nationale de la Recherche Scientifique.

Farrand, W.R. (1975a). Sediment analysis of a prehistoric rockshelter. Quaternary Research, 5, 1-21.

Farrand, W.R. (1975b). Analysis of the Abri Pataud sediments. In H.L. Movius, Jr. (Ed.), Excavation of the Abri Pataud, Les Eyzies (Dordogne) (pp. 27-68). Cambridge, MA: Peabody Museum of Archaeology and Ethnology, Harvard University.

Farrand, W.R. (1979). Chronology and palaeoenvironment of Levantine prehistoric sites as seen from sediment studies. Journal of Archaeological Science, 6, 369-392. 
Farrand, W.R. (1981). Pluvial climates and frost action during the last glacial cycle in the eastern Mediterranean-evidence from archaeological sites. In W.C. Mahaney (Ed.), Quaternary paleoclimate (pp. 393-410). Norwich, UK: GeoAbstracts, Ltd.

Farrand, W.R. (1985). Rockshelter and cave sediments. In J.K. Stein \& W.R. Farrand (Eds.), Archaeological sediments in context (pp. 21-39). Orono, ME: Center for the Study of Early Man.

Farrand, W.R. (1988). Integration of late Quaternary climatic records from France and Greece. In H.L. Dibble \& A. Montet-White (Eds.), Upper Pleistocene prehistory of western Eurasia (pp. 305-319). Philadelphia: University Museum, University of Pennsylvania.

Farrand, W.R. (1993). Discontinuity in the stratigraphic record: Snapshots from Franchthi Cave. In P. Goldberg, D.T. Nash, \& M.D. Petraglia (Eds.), Formation processes in archaeological context (pp. 85-96). Madison, WI: Prehistory Press.

Farrand, W.R. (1994). Confrontation of geological stratigraphy and radiometric dates from Upper Paleolithic sites in the Levant. In O. Bar-Yosef \& R.S. Kra (Eds.), Late Quaternary chronology and paleoclimates of the eastern Mediterranean (pp. 33-53). Tucson, AZ: Radiocarbon.

Farrand, W.R. (1995). Etude sédimentologique du remplissage de l'abri Pataud. In H.B. Bricker (Ed.), Le Paléolithique supérieur de l'abri Pataud (Dordogne): Les Fouilles de H. L. Movius, Jr. (pp. 3165), No. 50. Paris: Documents d'Archéologie Française.

Farrand, W.R. (2000). Depositional history of Franchthi Cave-sediments, stratigraphy, and chronology. Excavations at Franchthi Cave, Greece, Fascicle 12. Bloomington, IN: Indiana University Press.

Farrand, W.R. (2001). Depositional environments and site formation during the Mesolithic occupations of Franchthi Cave, Peloponnesos, Greece. In N. Galanidou \& C. Perlès (Eds.), The Greek Mesolithic: Problems and perspectives. London: British School at Athens Studies Series (in press).

Farrand, W.R., \& McMahon, J.P. (1997). History of the sedimentary infilling of Yarimburgaz Cave, Turkey. Geoarchaeology, 12, 537-565.

Goldberg, P. (1973). Sedimentology, stratigraphy, and paleoclimatology of Et-Tabun Cave, Mt. Carmel, Israel, Doctoral dissertation. Ann Arbor: University of Michigan (unpublished).

Guillien, Y., \& Lautridou, J-P. (1970). Recherches de gélifraction expérimentale du centre de géomorphologie. I. Calcaires des Charente: Essai au gel de quelques calcaires charentais, Bulletin du Centre de Géomorphologie de Caën No. 5. Paris: Centre National de la Recherche Scientifique.

Jelinek, A.J., Farrand, W.R., Haas, G., Horowitz, A., \& Goldberg, P. (1973). New excavations at the Tabun Cave, Mount Carmel, Israel, 1967-1972—-preliminary report. Paleorient, 1, 151-183.

Krinsley, D.H., \& Doorakamp, J.C. (1973). Atlas of quartz sand grain surfaces. Cambridge: Cambridge University Press.

Laville, H., Rigaud, J.-P., \& Sackett, J. (1980). Rockshelters of the Perigord. New York: Academic Press.

Movius, H.L., Jr. (1975). Excavation of the Abri Pataud, Les Eyzies (Dordogne), American School of Prehistoric Research, Bulletin 31. Cambridge, MA: Harvard University.

Santel, W.T. (1994). Die mittelpleistozänen Insectivora, Chiroptera, Rodentia und Lagomorpha aus der Yarimburgaz-Höhle, westlich von Istanbul (Türkisch Thrazien), Diplomarbeit. Bonn: RheinischeFriedrich-Wilhelms-Universität (unpublished).

Schiegl, S., Goldberg, P., Bar-Yosef, O., \& Weiner, S. (1996). Ash deposits in Hayonim and Kebara caves, Israel. Journal of Archaeological Science, 23, 763-781.

Stiner, M.C., Arsebük, G., \& Howell, F.C. (1996). Cave bears and Paleolithic artifacts in Yarimburgaz Cave,Turkey: Dissecting a palimpsest. Geoarchaeology, 11, 279-327.

White, S.E. (1976). Is frost action really only hydration shattering? A review. Arctic and Alpine Research, $81,1-6$.

Received May 30, 2000

Accepted for publication November 15, 2000 